\title{
Hemorragia pulmonar masiva presentada como muerte súbita neonatal.
}

\author{
Massive pulmonary haemorrhage presented as sudden \\ neonatal death.
}

J. Blanco Pampín y col.
Cuad Med Forense 2003;32:63-69

Antecedentes familiares sin interés. Madre primípara. Parto intrahospitalario. Nacimiento a término. Puntuación Apgar 3/4/5. Reanimada con ventilación positiva intermitente y oxigenoterapia. Profilaxis con vitamina K. Es dada de alta y remitida a su domicilio. A los cuatro días presenta un episodio de disnea intensa y tiraje intercostal, falleciendo a los pocos minutos de su ingreso en el centro hospitalario. Autopsia: lactante de sexo femenino, de $3200 \mathrm{~g}$ de peso y $45 \mathrm{~cm}$ de longitud. Como hallazgos fundamentales destacaban en el examen interno: Tráquea y bronquios principales se encontraban ocupados por abundante sangre fresca. Los pulmones estaban incrementados de peso (PD: 95 g, PI: 86 g), de consistencia carnosa y de color rojo oscuro (Figura $n^{\circ} \mathrm{I}$ ). El resto del examen interno sin anormalidades. El análisis toxicológico fue negativo. Microscópicamente los pulmones mostraban una amplia repleción eritrocitaria intraalveolar e intersticial, con ocupación de la luz bronquial por material hemático (Figura $n^{\circ} 2$ ). En los riñones se apreciaron amplios infiltrados hemorrágicos en el espacio intersticial de los túbulos contorneados (Figura $n^{\circ} 3$ ) y numerosos glomérulos ocupados por hematíes (Figura $n^{\circ} 4$ ) y en el hígado se observaban áreas de hemorragia centrolobulillar (Figura $n^{\circ} 5$ ).

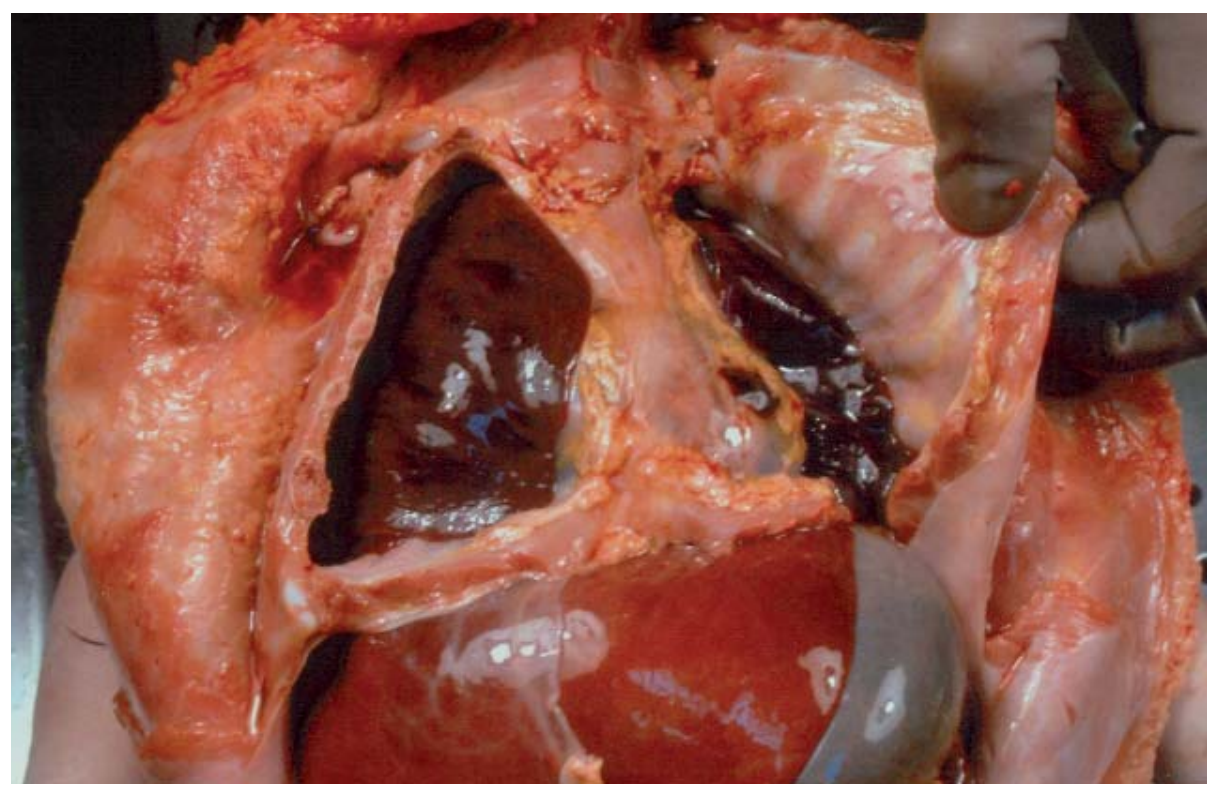

Figura 1.- Aspecto macroscópico de los pulmones. 


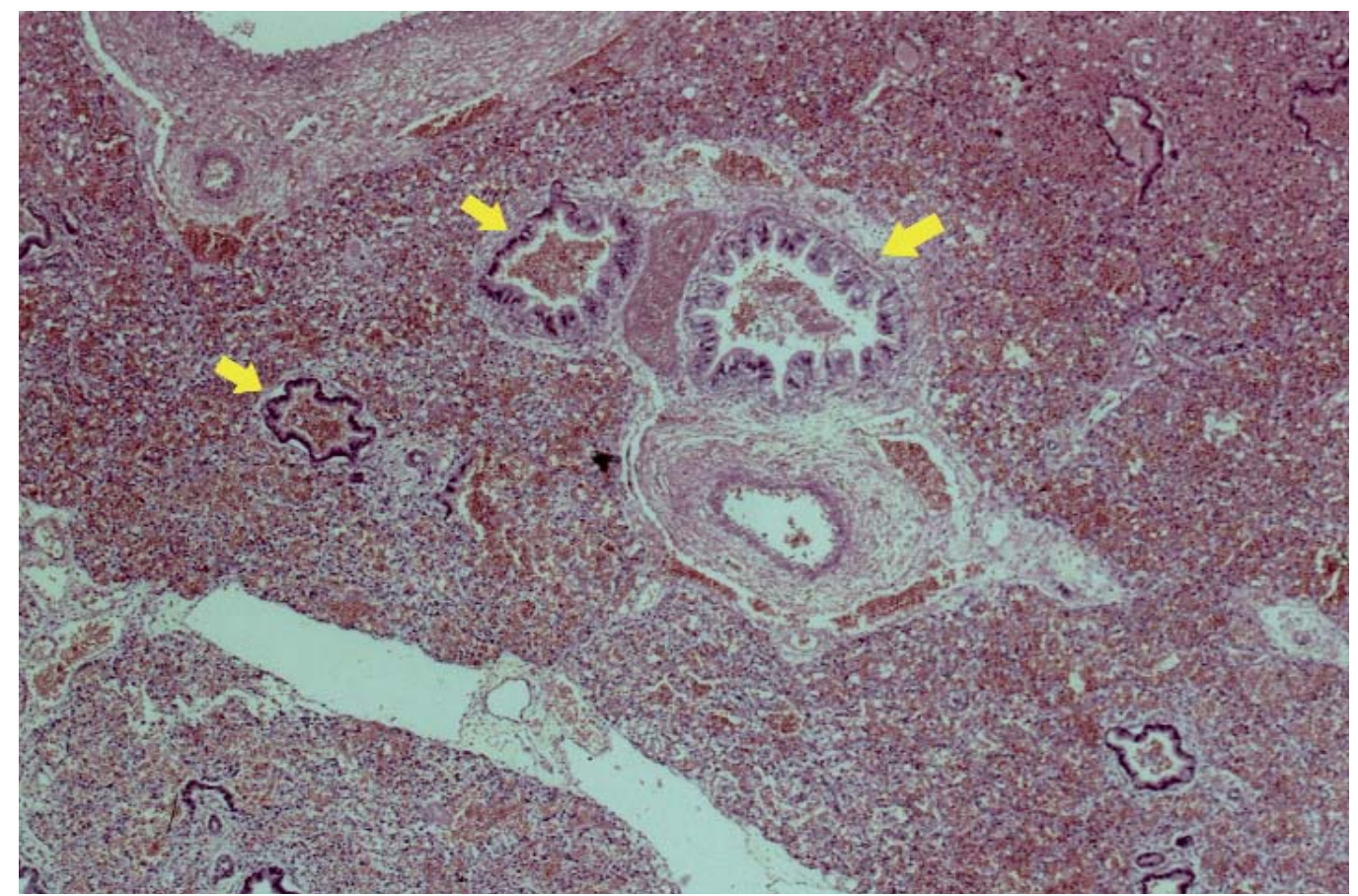

Figura 2.- Extravasación hemática pulmonar intralveolar e intersticial con ocupación de la luz bronquiolar (flechas) (H\&E 10x).

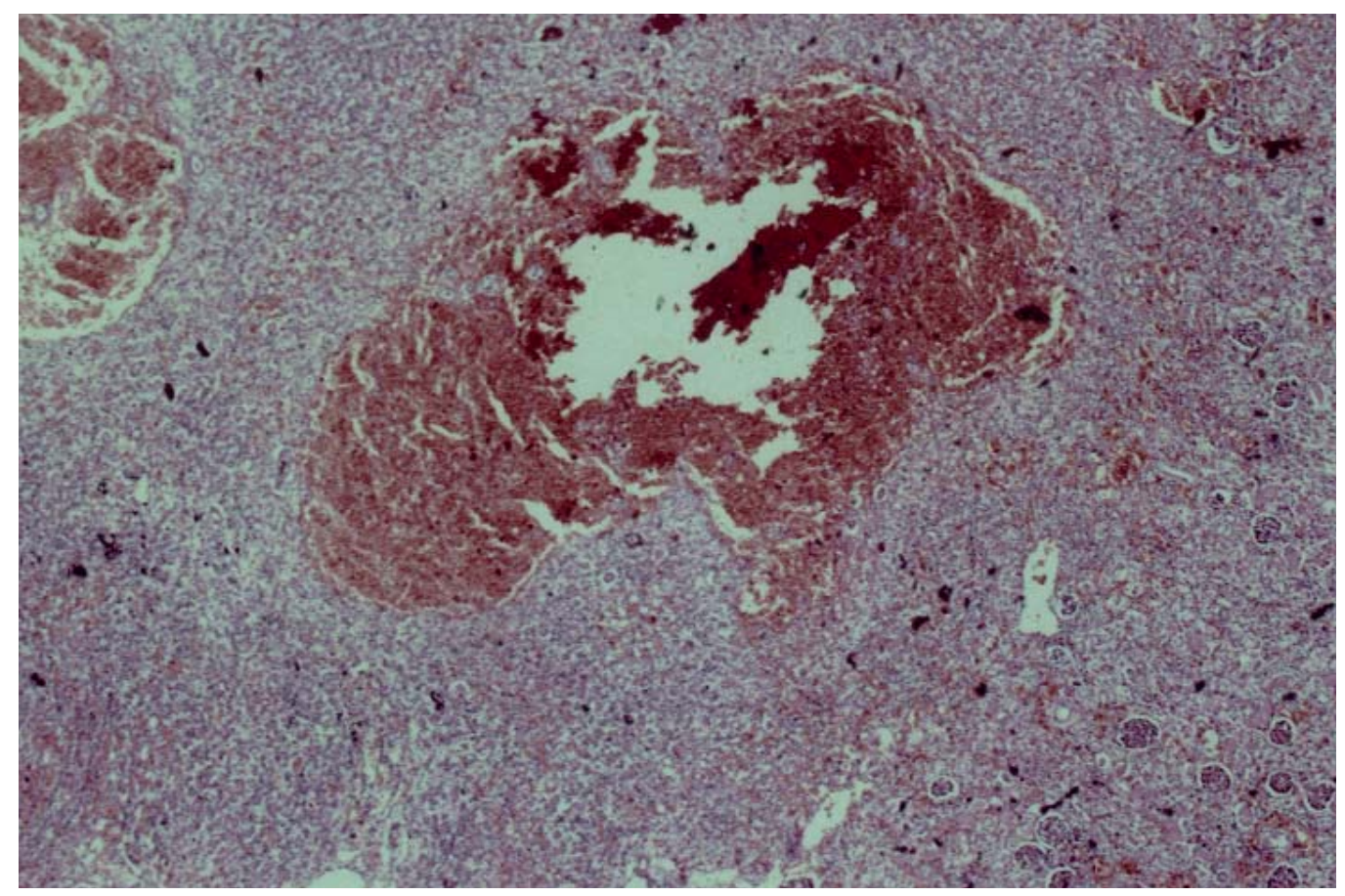

Figura 3.- Hemorragia intersticial renal (H\&E 10x). 


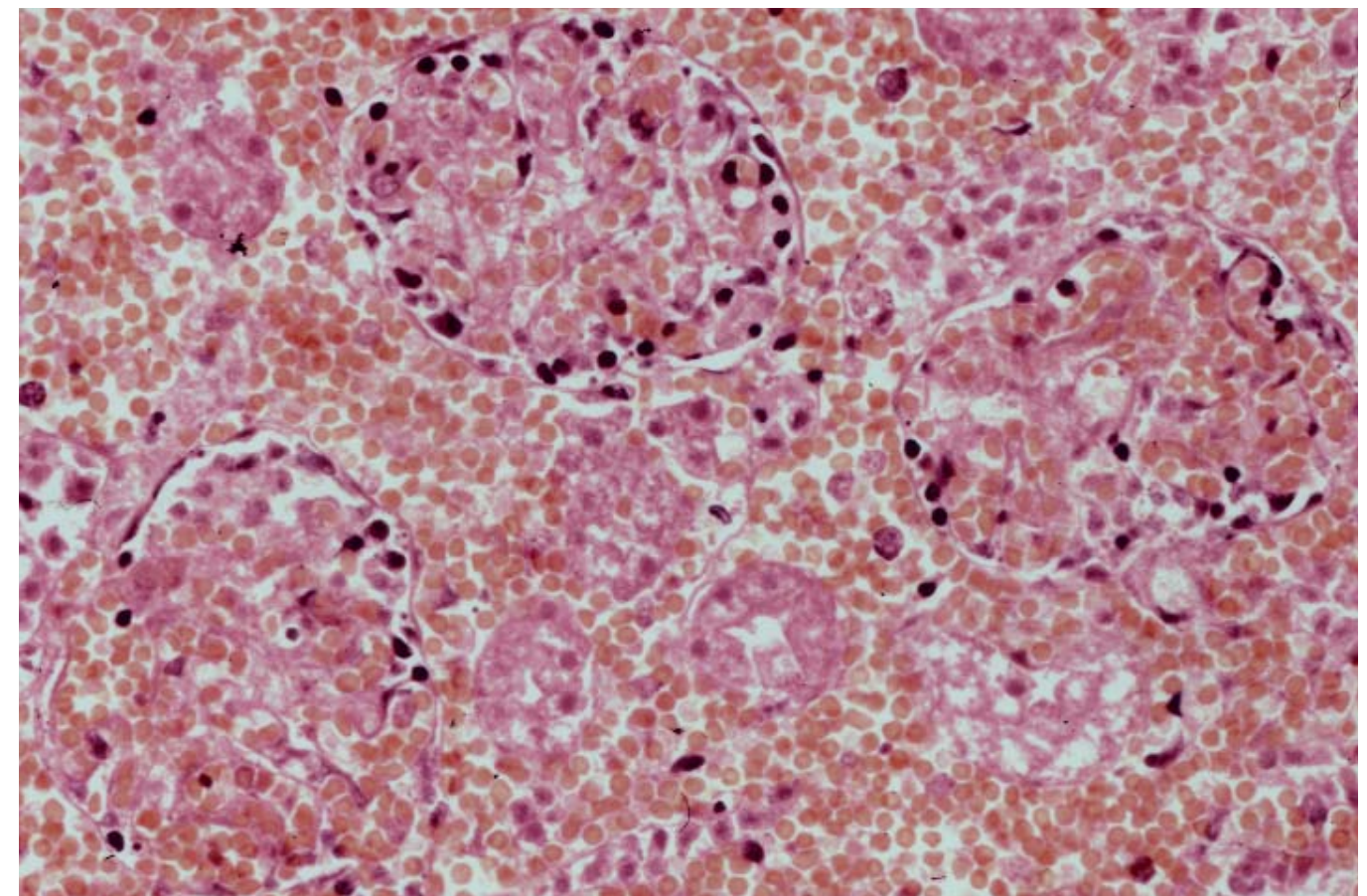

Figura 4.- Detalle histológico de hemorragia glomerular (H\&E 40x).

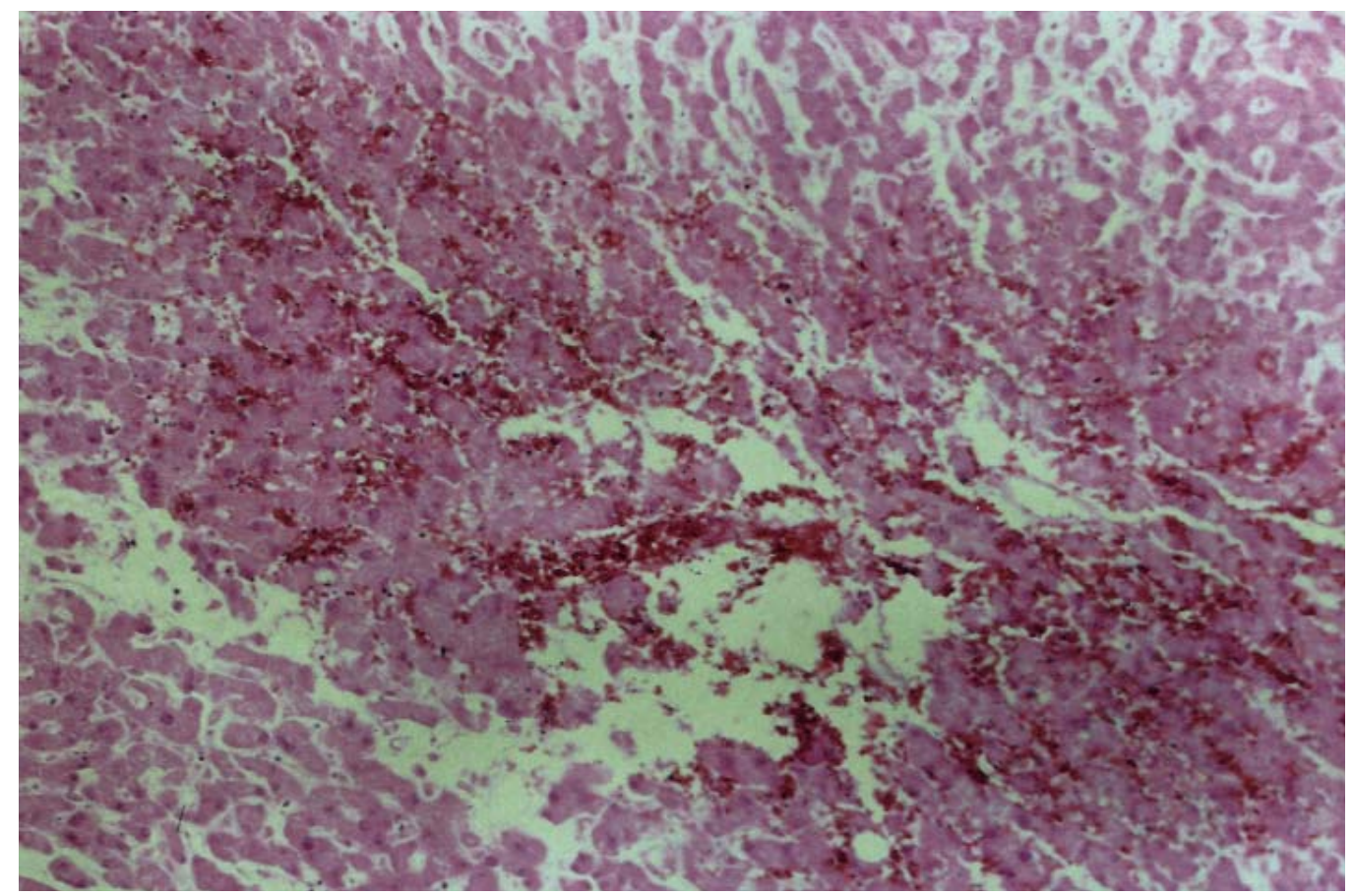

Figura 5.- Hígado mostrando zonas hemorrágicas (H\&E 40x). 